\title{
Severe hypoalbuminemia is a strong independent risk factor for acute respiratory failure in COPD: a nationwide cohort study
}

This article was published in the following Dove Press journal:

International Journal of COPD

17 June 2015

Number of times this article has been viewed

\author{
Char-Wen Chen ${ }^{1, *}$ \\ Yih-Yuan Chen ${ }^{2, *}$ \\ Chin-Li Lu ${ }^{3}$ \\ Solomon Chih-Cheng \\ $\mathrm{Chen}^{3}$ \\ Yi-Jen Chen ${ }^{1,4}$ \\ Ming-Shian Lin ${ }^{1,4}$ \\ Wei Chen ${ }^{1,5,6}$ \\ 'Division of Pulmonary and Critical \\ Care Medicine, Chia-Yi Christian \\ Hospital, Chiayi, ${ }^{2}$ Department of \\ Internal Medicine, Chia-Yi Christian \\ Hospital, Chiayi, ${ }^{3}$ Department of \\ Medical Research, Ditmanson Medical \\ Foundation, Chia-Yi Christian \\ Hospital, Chiayi, ${ }^{4}$ Department of \\ Respiratory Care, Chang Gung \\ University of Science and Technology, \\ Chiayi Campus; Changhua, ${ }^{5}$ College of \\ Nursing, Dayeh University, Changhua \\ ${ }^{6}$ Department of Respiratory Therapy, \\ China Medical University, Taichung, \\ Taiwan \\ *These authors contributed equally \\ to this work
}

Background: Acute respiratory failure (ARF) is a life-threatening event, which is frequently associated with the severe exacerbations of chronic obstructive pulmonary disease (COPD). Hypoalbuminemia is associated with increased mortality in patients with COPD. However, to date, little is known regarding whether or not hypoalbuminemia is a risk factor for developing ARF in COPD.

Methods: We conducted a retrospective cohort study using data from the National Health Insurance system of Taiwan. A total of 42,732 newly diagnosed COPD patients (age $\geq 40$ years) from 1997 to 2011 were enrolled. Among them, 1,861 (4.36\%) patients who had received albumin supplementation were defined as hypoalbuminemia, and 40,871 (95.6\%) patients who had not received albumin supplementation were defined as no hypoalbuminemia.

Results: Of 42,732 newly diagnosed COPD patients, 5,248 patients (12.3\%) developed ARF during the 6 years follow-up period. Patients with hypoalbuminemia were older, predominantly male, had more comorbidities, and required more steroid treatment and blood transfusions than patients without hypoalbuminemia. In a multivariable Cox regression analysis model, being elderly was the strongest independent risk factor for ARF (adjusted hazard ratio [HR]: 4.63, $P<0.001$ ), followed by hypoalbuminemia (adjusted HR: $2.87, P<0.001$ ). However, as the annual average dose of albumin supplementation was higher than $13.8 \mathrm{~g}$ per year, the risk for ARF was the highest (adjusted HR: 11.13, 95\% CI: 10.35-11.98, $P<0.001$ ).

Conclusion: Hypoalbuminemia is a strong risk factor for ARF in patients with COPD. Therefore, further prospective studies are required to verify whether or not albumin supplementation or nutritional support may help to reduce the risk of ARF in patients with COPD.

Keywords: COPD, acute respiratory failure, hypoalbuminemia

\section{Introduction}

Chronic obstructive pulmonary disease (COPD) is characterized by progressive, partially reversible airflow obstruction and lung hyperinflation with significant extrapulmonary manifestations and comorbid conditions. ${ }^{1-3}$ It is the fourth leading cause of chronic morbidity and mortality in the US ${ }^{4}$ and is projected to rank fifth in 2020 in terms of burden of disease worldwide. ${ }^{5,6}$ The natural course of COPD includes progressively declining lung function and a number of episodic exacerbations, which is defined as a worsening of respiratory symptoms requiring treatment with oral corticosteroids or antibiotics. ${ }^{7}$ Acute exacerbation (AE) is highly correlated with increased emergency department (ED) visits, respiratory failure, hospitalizations, and deaths in patients with COPD. ${ }^{8,9}$

Acute respiratory failure (ARF) is a common and life-threatening event, which is frequently associated with severe AE of COPD. ${ }^{10}$ Short-term or long-term outcomes
Division of Pulmonary and Critical Care Medicine, Chia-Yi Christian Hospital, 539 Jhongsiao Road, Chiayi 600, Taiwan Tel +886 52765041

Fax +886 527745 II

Email peteralfa2004@yahoo.com.tw
International Journal of COPD 2015:10 I| |47-I I54 
following ARF in COPD are poor, with a 2-year mortality rate of $49 \%$ and quite frequent intervals of readmission. ${ }^{11}$ In addition, several patients with COPD develop prolonged invasive ventilation following ARF, which is another critical issue in terms of health care in cases of COPD. ${ }^{12}$ Therefore, greater effort with regards to the prevention and recognition of COPD at risk of ARF is needed to decrease its everincreasing impact.

Hypoalbuminemia is the result of the combined effects of inflammation and inadequate protein and caloric intake in patients with chronic disease. ${ }^{13}$ Several studies have shown that hypoalbuminemia is associated with increased mortality in patients with COPD ${ }^{11,14,15}$ and is also an independent risk factor for a prolonged length of stay in AE of COPD. ${ }^{16}$ However, whether or not hypoalbuminemia is a risk factor for developing ARF in COPD remains known. ${ }^{17}$

This study attempts to determine if hypoalbuminemia is a risk factor for developing ARF in COPD. We conducted a retrospective cohort study using nationwide populationbased data, the National Health Insurance Research Database (NHIRD) of Taiwan.

\section{Materials and methods Data source}

Data in the present study were retrieved from LHID2000, a part of Taiwan's NHIRD. The NHIRD stores the claim data of Taiwan's National Health Insurance (NHI), which is a NHI program implemented by Taiwanese government in 1995. Enrollment in the NHI program is compulsory for all Taiwanese citizens and those residents with an Alien Resident Certificate. The NHI covers $>98 \%$ of the population in Taiwan and provides a broad range of comprehensive medical services. The NHIRD comprises information about diagnoses (coded in International Classification of Diseases, Version 9,Clinical Modification [ICD-9-CM]), clinical procedures, and medications for outpatient and inpatient visits as well as patients' sociodemographic status. LHID2000 is a randomized sample of one-million out of 23-million beneficiaries in Taiwan's NHIRD in 2000. By use of an encrypted unique identification number for each of the individuals, the claim data of the one-million patients from 1997 to 2011 were linked.

\section{Study population and study design}

We identified 65,421 incident COPD patients (aged $>40$ years) in LHID2000 from 1997 to 2011. They were first diagnosed as COPD (ICD-9-CM code: 491, 492, or 496) either based on their outpatient records as more than twice within the
365 days or at least once in inpatient records from 2000 to 2011 .

\section{Definition of hypoalbuminemia}

As we could not obtain the serum albumin level from the NHIRD, we used the frequency of albumin supplementation to define the severity of hypoalbuminemia in this study. Albumin supplementation is covered by our health insurance program when a patient's serum albumin level is $<2.5 \mathrm{~g} / \mathrm{dL}$ with underlying disease, such as liver cirrhosis, nephrotic syndrome, severe burn, or shock. However, in actual clinical practice, many physicians prescribe albumin to patients only because of low serum albumin level $(<2.5 \mathrm{~g} / \mathrm{dL})$, but do not consider the underlying disease.

To avoid baseline inequity of albumin level, we excluded those who had been supplied with albumin before a COPD diagnosis was made. To focus on the role of malnutrition to the development of respiratory failure in COPD patients, patients with prior histories of liver cirrhosis or nephritic syndrome were excluded (Figure 1). A total of 42,732 newly diagnosed COPD patients were enrolled into the data analysis. Among them, 1,861 (4.36\%) patients who had been supplied with albumin during their follow-up period and were classified as the hypoalbuminemia group; 40,871 $(95.6 \%)$ patients had never been supplied with albumin were classified as control group. The annual cumulative amount of albumin injections was also calculated. Patients in hypoalbuminemia group were further classified into two groups $(\leq 13.8 \mathrm{~g}$ per year, $>13.8 \mathrm{~g}$ per year; $13.8 \mathrm{~g}$ per year is the median amount of albumin supplementation) according to the amount of albumin they received. Severe hypoalbuminemia was defined as patients receiving albumin supplementation of 1,250 mg per year or more. The follow-up period of this study started from the date of a first diagnose of COPD (index date) to the date of the occurrence of ARF, attrition from NHI, or December 31, 2011, whichever came first.

\section{Definitions of comorbidities}

The occurrence of ARF was defined as diagnosis of ARF (ICD-9-CM code: 518.81) and use of invasive or noninvasive mechanical ventilations during hospitalization. Other potential confounding factors were also identified, including sociodemographic characteristics (ie, age, sex, occupation, and urbanization level of living area), comorbidities related to the risk of ARF (ie, end-stage renal disease [ESRD], diabetes mellitus, hypertension, ischemic heart disease [IHD], stroke, Parkinson's disease, malignancies), and treatments such as use 


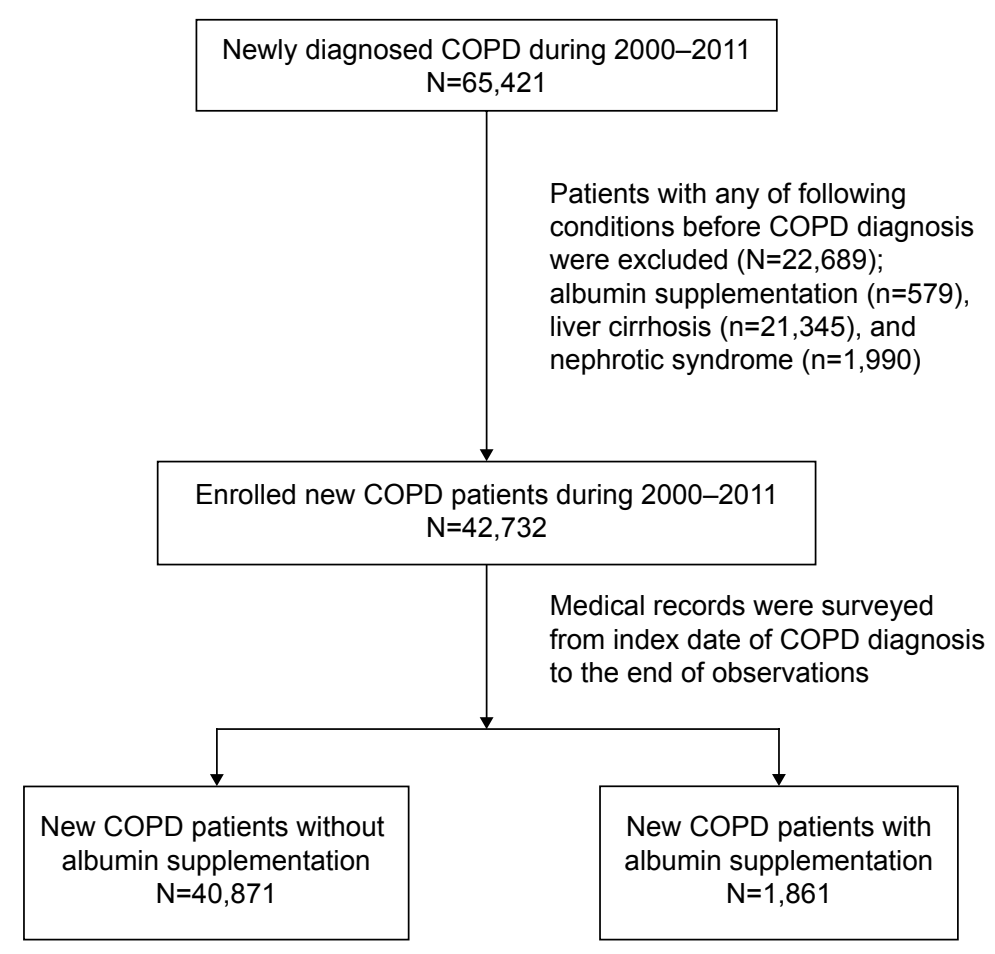

Figure I Flow chart of patient enrollment.

of steroid and blood transfusion. The occupations of patients were presented as four types according to the classification of beneficiaries in NHI; type I included civil servants, most employees, employers, and independently practicing professionals or technicians; type II included workers without particular employers or those who were self-employed, seamen or master mariners serving on foreign vessels; type III were mostly farmers and fishermen; type IV-VI mainly included members of low-income families, veterans and their families, and others. An index of the urbanization level of Taiwan's townships, which was essentially developed for large-scale surveys in Taiwan, was applied in this study. ESRD and malignancies were identified as a patient registered in catastrophic illness database in NHIRD for dialysis (ICD9-CM code: 585.xx) or for broad range of malignancies (ICD-9-CM codes: 140.xx-239.xx), respectively. Diabetes (ICD-9-CM code: $250 . \mathrm{xx}$ ), hypertension (ICD-9-CM codes: 401.xx or 402.xx), IHD (ICD-9-CM codes: 410.xx-414.xx), stroke (ICD-9-CM codes: 430.xx-438.xx), and Parkinson's disease (ICD-9-CM code: 232.xx) were identified if they were presented as diagnoses in patients' outpatient records more than twice within the 365 days or at least once in inpatient records from index date to the end of follow-up. In addition, we also counted the annual number of ED visits and hospitalizations of study patients. The annual number of ED visits and hospitalizations were dichotomized by median. Use of steroid and blood transfusion were also identified by surveying the patients' medication records in NHIRD.

\section{Statistical analysis}

Sociodemographic characteristics, comorbidities, and clinical procedures including medications were compared between albumin group and control group; similar comparisons were also performed between the group with and without development of ARF. Categorical variables were compared by using chi-square test, and continuous variables were compared by Student's $t$-test. Cox proportional hazard regression model was performed to elucidate the associations of albumin supplementation and other risk factors with the risk of developing ARF. Univariable and multivariable regression analyzes were both performed to yield the crude hazard ratios (HRs), adjusted HRs, and their $95 \%$ of confidence intervals. Adjusted HR of albumin supplementation on the risk of ARF was estimated after adjustment for aforementioned risk factors including sociodemographic characteristics, comorbidities, use of steroid, receive of blood transfusion. Finally, a Cox regression analysis was further presented to delineate how the adjusted HR varied with the dose of albumin supplementation compared with those who had never been supplied with albumin. Data management and data analyzes were performed by using SAS/STAT ${ }^{\circledR}$ software, version 9.3 for Windows (SAS Institute Inc., Cary, NC, USA.). 


\section{Results}

A total of 42,732 newly diagnosed COPD patients $(57 \%$ male, mean age: 66 years) were enrolled in this study. Among them, $12.3 \%$ of the patients $(n=5,248)$ developed ARF during the 6-year follow-up period.
The mean follow-up period of hypoalbuminemia group was 5.6 years, which was shorter than the control group (6.2 years). Table 1 shows that patients with hypoalbuminemia were older and more likely to be male, have a type-III occupation (ie, farmers, fishermen, low-income family,

Table I Demographic and clinical characteristics of COPD patients with and without hypoalbuminemia

\begin{tabular}{|c|c|c|c|}
\hline Characteristics & No hypoalbuminemia $(n=40,87 I)$ & Hypoalbuminemia $(n=I, 86 I)$ & $P$-value \\
\hline \multicolumn{4}{|c|}{ Duration of follow-up, months } \\
\hline Mean \pm SD & $73.96 \pm 44.08$ & $67.21 \pm 48.27$ & $<0.001$ \\
\hline \multicolumn{4}{|l|}{ Sex } \\
\hline Female & $17,660(43.21)$ & $601(32.29)$ & \multirow[t]{2}{*}{$<0.001$} \\
\hline Male & $23,211(56.79)$ & $\mathrm{I}, 260(67.7 \mathrm{I})$ & \\
\hline \multicolumn{4}{|l|}{ Age (years) } \\
\hline $40-54$ & $10,268(25.12)$ & $120(6.45)$ & \multirow[t]{4}{*}{$<0.001$} \\
\hline $55-64$ & $8,463(20.71)$ & $191(10.26)$ & \\
\hline $65-74$ & $|0,75|(26.30)$ & $544(29.23)$ & \\
\hline $75+$ & II,389 (27.87) & $\mathrm{I}, 006(54.06)$ & \\
\hline Mean \pm SD & $65.69 \pm 13.23$ & $74.66 \pm 10.78$ & $<0.001$ \\
\hline \multicolumn{4}{|l|}{ Occupation* } \\
\hline I & $15,368(37.60)$ & $546(29.34)$ & \multirow[t]{4}{*}{$<0.001$} \\
\hline ॥ & $7,07 \mid(17.30)$ & $199(10.69)$ & \\
\hline III & $10,396(25.44)$ & $598(32.13)$ & \\
\hline$I V-V I$ & $8,036(19.66)$ & $518(27.83)$ & \\
\hline \multicolumn{4}{|c|}{ Urbanization of living area } \\
\hline I (highest) & $10,865(26.71)$ & $432(23.29)$ & \multirow[t]{4}{*}{$<0.001$} \\
\hline II & II,295 (27.77) & $439(23.67)$ & \\
\hline III & $6,728(16.54)$ & $336(18.11)$ & \\
\hline IV (lowest) & I I,785 (28.97) & $648(34.93)$ & \\
\hline \multicolumn{4}{|l|}{ ESRD } \\
\hline Without & $40,508(99.11)$ & I,83I (98.39) & \multirow[t]{2}{*}{$<0.001$} \\
\hline With & $363(0.89)$ & $30(1.61)$ & \\
\hline \multicolumn{4}{|l|}{ DM } \\
\hline Without & $27,817(68.06)$ & I,083 (58.19) & \multirow[t]{2}{*}{$<0.001$} \\
\hline With & |3,054 (31.94) & $778(4 \mathrm{I} .8 \mathrm{I})$ & \\
\hline \multicolumn{4}{|l|}{ Hypertension } \\
\hline Without & $|3,7| \mid$ (33.55) & $436(23.43)$ & \multirow[t]{2}{*}{$<0.001$} \\
\hline With & $27,160(66.45)$ & $\mathrm{I}, 425$ (76.57) & \\
\hline \multicolumn{4}{|l|}{ IHD } \\
\hline Without & $24,146(59.08)$ & $822(44.17)$ & \multirow[t]{2}{*}{$<0.001$} \\
\hline With & $16,725(40.92)$ & $\mathrm{I}, 039$ & \\
\hline \multicolumn{4}{|l|}{ Stroke } \\
\hline Without & 34,898 (85.39) & $\mathrm{I}, 26 \mathrm{I}(67.76)$ & \multirow[t]{2}{*}{$<0.001$} \\
\hline With & $5,973(\mid 4.6 I)$ & $600(32.24)$ & \\
\hline \multicolumn{4}{|l|}{ Parkinson disease } \\
\hline Without & $38,429(94.03)$ & I,653 (88.82) & \multirow[t]{2}{*}{$<0.00$ I } \\
\hline With & $2,442(5.97)$ & $208(11.18)$ & \\
\hline Malignancy & & & \\
\hline Without & 37,802 (92.49) & I,577 (84.74) & $<0.001$ \\
\hline With & $3,069(7.5 \mathrm{I})$ & $284(15.26)$ & \\
\hline Steroid & & & \\
\hline Without & 36,764 (89.95) & I,623 (87.2I) & $<0.001$ \\
\hline With & $4,107(10.05)$ & $238(12.79)$ & \\
\hline Blood transfusion & & & \\
\hline Without & 34,204 (83.69) & $300(16.12)$ & $<0.001$ \\
\hline With & $6,667(|6.3|)$ & $\mathrm{I}, 56 \mathrm{I}(83.88)$ & \\
\hline ARF & & & \\
\hline Without & $36,578(97.58)$ & $4,293(81.80)$ & $<0.001$ \\
\hline With & $906(2.42)$ & $955(18.20)$ & \\
\hline
\end{tabular}

Notes: Data values are presented as number (\%) unless otherwise stated. *The occupations of patients were presented as four types according to the classification of beneficiaries in $\mathrm{NHI}$; type I included civil servants, most employees, employers, and independently practicing professionals or technicians; type II included workers without particular employers or those who were self-employed, seamen or master mariners serving on foreign vessels; type III were mostly farmers and fishermen; type IV-VI mainly included members of low-income families, veterans and their families, and others.

Abbreviations: ARF, acute respiratory failure; ESRD, end-stage renal disease; DM, diabetes mellitus; IHD, ischemic heart disease; NHI, Taiwan's National Health Insurance; SD, standard deviation. 
veterans and families, and others), and live in less urbanized areas. They also had more chronic diseases (including diabetes, hypertension, IHD, stroke, Parkinson's disease, and malignancies) and were more likely to receive treatments such as steroids and blood transfusion as compared with the control group. However, despite these differences, the crude mortality rates were similar between two groups.

Table 2 presents the cumulative risk and crude HR of ARF for patients in different subgroups. In the univariable analysis, patients with hypoalbuminemia during the follow-up period

Table 2 Demographic and clinical characteristics of COPD patients with $(n=5,248)$ and without $(n=37,484)$ developing ARF

\begin{tabular}{|c|c|c|c|c|}
\hline \multirow[t]{2}{*}{ Characteristics } & \multicolumn{2}{|l|}{ ARF } & \multirow[t]{2}{*}{ Crude HR (95\% Cl) } & \multirow[t]{2}{*}{$P$-value } \\
\hline & Without, \% & With, \% & & \\
\hline \multicolumn{5}{|l|}{ Hypoalbuminemia } \\
\hline Without & 89.5 & 10.5 & Ref & \\
\hline With & 48.68 & 51.32 & $5.35(4.98-5.74)$ & $<0.001$ \\
\hline \multicolumn{5}{|l|}{ Steroid } \\
\hline Without & 89.09 & 10.91 & Ref & \\
\hline With & 75.6 & 24.4 & $2.25(2.10-2.4 \mathrm{I})$ & $<0.001$ \\
\hline \multicolumn{5}{|l|}{ Blood transfusion } \\
\hline Without & 91.09 & 8.91 & Ref & \\
\hline With & 73.6 & 26.4 & $2.70(2.50-2.86)$ & $<0.001$ \\
\hline \multicolumn{5}{|l|}{ Sex } \\
\hline Female & 90.46 & 9.54 & Ref & \\
\hline Male & 85.67 & 14.33 & I.55 (I.46-I.64) & $<0.001$ \\
\hline \multicolumn{5}{|l|}{ Age (years) } \\
\hline $40-54$ & 97.66 & 2.34 & Ref & \\
\hline $55-64$ & 94.25 & 5.75 & $2.59(2.22-3.02)$ & $<0.001$ \\
\hline $65-74$ & 85.68 & 14.32 & $6.18(5.40-7.08)$ & $<0.001$ \\
\hline $75+$ & 76.68 & 23.32 & $11.33(9.93-12.92)$ & $<0.001$ \\
\hline \multicolumn{5}{|l|}{ Occupation* } \\
\hline I & 90.86 & 9.14 & Ref & \\
\hline II & 93.04 & 6.96 & $0.77(0.69-0.85)$ & $<0.001$ \\
\hline III & 83.9 & 16.1 & $1.73(1.62-1.86)$ & $<0.001$ \\
\hline $\mid \mathrm{IV}-\mathrm{VI}$ & 82.25 & 17.75 & $1.88(1.75-2.02)$ & $<0.001$ \\
\hline \multicolumn{5}{|c|}{ Urbanization of living area } \\
\hline I (highest) & 90.33 & 9.67 & Ref & \\
\hline II & 89.08 & 10.92 & $1.12(1.03-1.21)$ & 0.007 \\
\hline III & 86.93 & 13.07 & $1.37(1.26-1.50)$ & $<0.001$ \\
\hline IV (lowest) & 84.43 & 15.57 & $1.60(1.49-1.73)$ & $<0.001$ \\
\hline \multicolumn{5}{|l|}{ ESRD } \\
\hline Without & 87.81 & 12.19 & Ref & \\
\hline With & 77.86 & 22.14 & I.67 (I.35-2.07) & $<0.001$ \\
\hline \multicolumn{5}{|l|}{ DM } \\
\hline Without & 89.3 & 10.7 & Ref & \\
\hline With & 84.42 & 15.58 & I.36 (I.29-I.44) & $<0.001$ \\
\hline \multicolumn{5}{|l|}{ Hypertension } \\
\hline Without & 91.59 & 8.41 & Ref & \\
\hline With & 85.8 & 14.2 & I.52 (I.42-I.62) & $<0.001$ \\
\hline \multicolumn{5}{|l|}{ IHD } \\
\hline Without & 90.21 & 9.79 & Ref & \\
\hline With & 84.22 & 15.78 & $1.39(1.32-1.47)$ & $<0.001$ \\
\hline \multicolumn{5}{|l|}{ Stroke } \\
\hline Without & 90.87 & 9.13 & Ref & \\
\hline With & 70.41 & 29.59 & $3.16(2.99-3.34)$ & $<0.001$ \\
\hline \multicolumn{5}{|l|}{ Parkinson disease } \\
\hline Without & 88.49 & $|1.5|$ & Ref & \\
\hline With & 76.04 & 23.96 & $2.00(1.84-2.17)$ & $<0.001$ \\
\hline \multicolumn{5}{|l|}{ Malignancy } \\
\hline Without & 87.84 & 12.16 & Ref & \\
\hline With & 86.28 & 13.72 & $0.99(0.90-1.09)$ & 0.818 \\
\hline
\end{tabular}

Notes: *The occupations of patients were presented as four types according to the classification of beneficiaries in NHI; type I included civil servants, most employees, employers, and independently practicing professionals or technicians; type II included workers without particular employers or those who were self-employed, seamen or master mariners serving on foreign vessels; type III were mostly farmers and fishermen; type IV-VI major included members of low-income families, veterans and their families, and others. Abbreviations: ARF, acute respiratory failure; HR, hazard ratio; $\mathrm{Cl}$, confidence interval; Ref, reference group; ESRD, end-stage renal disease; DM, diabetes mellitus; IHD, ischemic heart disease; NHI, Taiwan's National Health Insurance. 
Table 3 Adjusted hazard ratio of ARF related to patient's characteristics

\begin{tabular}{|c|c|c|c|}
\hline Parameters & AHR & $95 \% \mathrm{Cl}$ & $P$-value \\
\hline \multicolumn{4}{|l|}{ Hypoalbuminemia } \\
\hline With vs without & 2.87 & $2.65-3.10$ & $<0.001$ \\
\hline \multicolumn{4}{|l|}{ Use of steroid } \\
\hline Ever vs never & 1.97 & $1.84-2.11$ & $<0.001$ \\
\hline \multicolumn{4}{|l|}{ Blood transfusion } \\
\hline Ever vs never & 0.74 & $0.70-0.79$ & $<0.001$ \\
\hline \multicolumn{4}{|l|}{ Age (years) } \\
\hline $40-54$ & Ref & & \\
\hline $55-64$ & 2.36 & $2.02-2.75$ & $<0.001$ \\
\hline $65-74$ & 4.63 & $4.02-5.34$ & $<0.001$ \\
\hline $75+$ & 7.48 & $6.5 \mathrm{I}-8.60$ & $<0.001$ \\
\hline \multicolumn{4}{|l|}{ Sex } \\
\hline Male vs female & 1.32 & I.24-I.40 & $<0.001$ \\
\hline \multicolumn{4}{|l|}{ Occupation* } \\
\hline I & Ref & & \\
\hline$\|$ & 1.01 & $0.91-1.12$ & 0.866 \\
\hline III & 0.95 & $0.87-1.03$ & 0.222 \\
\hline IV-VI & 1.08 & $1.00-1.16$ & 0.060 \\
\hline \multicolumn{4}{|c|}{ Urbanization of living area } \\
\hline I (highest) & Ref & & \\
\hline$\|$ & 1.06 & $0.97-1.15$ & 0.188 \\
\hline III & 1.17 & $1.07-1.28$ & 0.001 \\
\hline IV (lowest) & 1.25 & I.I5-1.37 & $<0.001$ \\
\hline \multicolumn{4}{|l|}{ ESRD } \\
\hline With vs without & 1.27 & $1.02-1.57$ & 0.031 \\
\hline \multicolumn{4}{|l|}{ DM } \\
\hline With vs without & 1.12 & $1.06-1.18$ & 0.000 \\
\hline \multicolumn{4}{|l|}{ Hypertension } \\
\hline With vs without & 0.83 & $0.77-0.89$ & $<0.001$ \\
\hline \multicolumn{4}{|l|}{ IHD } \\
\hline With vs without & 0.93 & $0.88-0.99$ & 0.019 \\
\hline \multicolumn{4}{|l|}{ Parkinson's disease } \\
\hline With vs without & I.II & $1.02-1.20$ & 0.021 \\
\hline \multicolumn{4}{|l|}{ Stroke } \\
\hline With vs without & 1.90 & I.79-2.02 & $<0.001$ \\
\hline \multicolumn{4}{|l|}{ Malignancy } \\
\hline With vs without & 0.72 & $0.65-0.79$ & $<0.001$ \\
\hline
\end{tabular}

Notes: *The occupations of patients were presented as four types according to the classification of beneficiaries in $\mathrm{NHI}$; type I included civil servants, most employees, employers, and independently practicing professionals or technicians; type II included workers without particular employers or those who were self-employed, seamen or master mariners serving on foreign vessels; type III were mostly farmers and fishermen; type IV-VI major included members of low-income families, veterans and their families, and others.

Abbreviations: ARF, acute respiratory failure; AHR, adjusted hazard ratio; $\mathrm{Cl}$, confidence interval; Ref, reference group; ESRD, end-stage renal disease; DM, diabetes mellitus; IHD, ischemic heart disease; NHI, Taiwan's National Health Insurance.

were 5.35 times more likely to develop ARF than controls. Other covariates listed in Table 2 were also associated with the risk of ARF.

Adjusted HR estimated in the multivariable Cox regression analysis is presented in Table 3. After adjustment for sociodemographic factors, comorbidities, treatment of steroid and blood transfusion, the HR of ARF related to hypoalbuminemia attenuated but was still statistical significant (AHR:

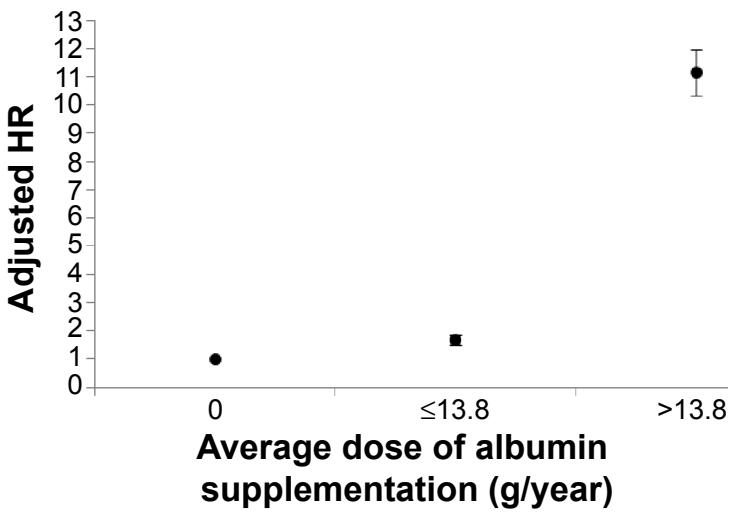

Figure 2 Adjusted hazard ratios of risk of acute respiratory failure associated with annual average dose of albumin supplementation.

Note: Severe hypoalbuminemia is defined as average dose of albumin supplementation $>13.8$ g per year.

Abbreviations: HR, hazard ratio; yr, year.

2.87 [95\% CI: 2.65-3.10]). In addition, older age, male sex, treatment of steroid, less urbanized living areas, comorbid with ESRD, diabetes, Parkinson's disease, and stroke were related to a higher risk of ARF; nevertheless, patients who were comorbid with hypertension, IHD, and malignancies and had received blood transfusion were less likely to develop ARF after adjustment for other risk factors.

Figure 2 shows that adjusted HR of ARF increased with the annual average dose of albumin supplementation. If the average dose of albumin injection was lower than $13.8 \mathrm{~g}$ per year, the adjusted HR slightly increased to 1.69 (95\% CI: 1.52-1.87). If the annual average dose was higher than $13.8 \mathrm{~g}$ per year, which was defined as severe hypoalbuminemia, the risk was even higher (AHR: 11.13, [95\% CI: 10.35-11.98]) than no supplementation of albumin.

\section{Discussion}

To the best of our knowledge, this is the largest cohort of data concerning the risk of hypoalbuminemia in the development of ARF in patients with COPD. Our data showed that being elderly was the strongest independent risk factor for ARF (adjusted HR: 4.63, $P<0.001$ ), followed by hypoalbuminemia (adjusted HR: 2.87, $P<0.001$ ). However, as the annual average dose of albumin supplementation was higher than $13.8 \mathrm{~g}$ per year, which was defined as severe hypoalbuminemia, the risk for ARF was the highest (AHR:11.13, 95\% CI: $10.35-11.98, P<0.001)$.

The outcome is poor when a COPD patient develops ARF during an AE. ${ }^{18}$ Over one-third of patients died during hospitalization ${ }^{19}$ and survival is particularly reduced (50\%) when mechanical ventilation is required. ${ }^{18,20}$ Furthermore, the long-term survival is still poor in patients receiving noninvasive ventilation, showing that the 5 -year survival rate is 
only $23.7 \% .^{21}$ Thus, the prevention of exacerbations or ARF is now recognized as a primary goal of maintenance therapy for COPD. ${ }^{22}$ According to the Global Initiative for Chronic Obstructive Lung Disease guideline, vaccinations and several pharmacotherapies, such as long acting bronchodilators and inhaled corticosteroid, have been proved to be effective in the prevention of exacerbation of COPD. ${ }^{23,24}$ Nutrition has been the topic of extensive scientific research in COPD; however, clinical awareness of the impact of dietary habits and nutritional status on COPD progression and outcome is relatively limited. ${ }^{25}$ Based on the findings of this study, we suggest that COPD patients should have a routine nutritional assessment and consultant once their diagnosis has been made. However, it may require further prospective study to verify whether albumin supplementation or nutritional support may reduce the risk of ARF in patients with COPD.

The prevalence and features of COPD patients with AE have been studied extensively, ${ }^{26-29}$ but the risk factors for ARF are poorly identified. In the current study, we showed that the comorbidities related to the risk of ARF included ESRD, diabetes mellitus, stroke, Parkinson's disease and stroke, which is compatible with previous studies. ${ }^{30}$ In addition, COPD patients requiring systemic steroid or blood transfusion represent more severe disease condition, which is reasonably associated with higher risks of ARF. ${ }^{31,32}$

Serum albumin level is one of the assessment tests for malnutrition in COPD. ${ }^{33}$ However, few studies have focused on the role of serum albumin level as it relates to the development of ARF in COPD. There have been a number of studies investigating the association between albumin level and disease outcomes. For general hospitalized patients, lower serum albumin levels correlate with an increased risk of morbidity and mortality. ${ }^{34}$ Hypoalbuminemia has also been shown as an important prognostic factor among a variety of diseases, such as severe sepsis, burns, ${ }^{35}$ and regional enteritis (Crohn disease). ${ }^{36}$ It is also associated with an increased risk of reintubation in postanesthetic general surgical patients. ${ }^{37}$ In the current study, we confirmed that hypoalbuminemia is a strong risk factor for ARF in COPD.

This study had both strengths and limitations. Major strengths include the large number of COPD patients as well as a long follow-up period (average 6 years) in the NHIRD cohort. A limitation of the study is that information about COPD diagnosis was derived from ICD-9-CM and may not be completely accurate. Second, although we have adjusted the potential confounding factors and comorbidities related to the risk of ARF, the other confounding factors, such as body mass index, pulmonary function test were not available from this dataset. Third, the policy of albumin supplementation is offered by national health system in Taiwan, which limits the generalizability of such study to other health care systems.

In conclusion, hypoalbuminemia is a strong risk factor for ARF in patients with COPD. Severe hypoalbuminemia, which is defined as annual average dose of albumin supplementation higher than $13.8 \mathrm{~g}$ per year, is the strongest risk factor. Therefore, further prospective studies are needed to verify whether albumin supplementation or nutritional support may reduce the risk of ARF in patients with COPD.

\section{Disclosure}

The authors report no conflicts of interest in this work.

\section{References}

1. Schols AM, Slangen J, Volovics L, Wouters EF. Weight loss is a reversible factor in the prognosis of chronic obstructive pulmonary disease. Am J Respir Crit Care Med. 1998;157:1791-1797.

2. Maltais F, Simard AA, Simard C, Jobin J, Desgagnés P, LeBlanc P. Oxidative capacity of the skeletal muscle and lactic acid kinetics during exercise in normal subjects and in patients with COPD. Am J Respir Crit Care Med. 1996;153:288-293.

3. Garcia-Rio F, Miravitlles M, Soriano JB, et al; EPI-SCAN Steering Committee. Systemic inflammation in chronic obstructive pulmonary disease: a population-based study. Respir Res. 2010;11:63.

4. Adams PF, Marano MA. Current estimates from the National Health Interview Survey, 1994. Vital Health Stat. 1995;10:261-520.

5. Mannino DM, Kiriz VA. Changing the burden of COPD mortality. Int J Chron Obstruct Pulmon Dis. 2006;1:219-233.

6. Murray CJ, Lopez AD. Mortality by cause for eight regions of the world: Global Burden of Disease Study. Lancet. 1997;349:1269-1276.

7. Burge PS, Calverley PM, Jones PW, Spencer S, Anderson JA, Maslen TK. Randomised, double blind, placebo controlled study of fluticasone propionate in patients with moderate to severe chronic obstructive pulmonary disease: the ISOLDE trial. BMJ. 2000;320:1297-1303.

8. Wedzicha JA, Seemungal TA. COPD exacerbations: defining their cause and prevention. Lancet. 2007;370:786-796.

9. MacIntyre N, Huang YC. Acute exacerbations and respiratory failure in chronic obstructive pulmonary disease. Proc Am Thorac Soc. 2008;5: 530-535.

10. Calverley PM. Respiratory failure in chronic obstructive pulmonary disease. Eur Respir J Suppl. 2003;47:26s-30s.

11. Connors AF Jr, Dawson NV, Thomas C, et al. Outcomes following acute exacerbation of severe chronic obstructive lung disease. The SUPPORT investigators (Study to understand prognoses and preferences for outcomes and risks of treatments). Am J Respir Crit Care Med. 1996;154:959-967.

12. Quinnell TG, Pilsworth S, Shneerson JM, Smith IE. Prolonged invasive ventilation following acute ventilatory failure in COPD: weaning results, survival, and the role of noninvasive ventilation. Chest. 2006; 129:133-139.

13. Don BR, Kaysen G. Serum albumin: relationship to inflammation and nutrition. Semin Dial. 2004;17:432-437.

14. Hasegawa W, Yamauchi Y, Yasunaga H, et al. Factors affecting mortality following emergency admission for chronic obstructive pulmonary disease. BMC Pulm Med. 2014;14:151.

15. Haja Mydin H, Murphy S, Clague H, Sridharan K, Taylor IK. Anemia and performance status as prognostic markers in acute hypercapnic respiratory failure due to chronic obstructive pulmonary disease. Int $J$ Chron Obstruct Pulmon Dis. 2013;8:151-157.

16. Wang Y, Stavem K, Dahl FA, Humerfelt S, Haugen T. Factors associated with a prolonged length of stay after acute exacerbation of chronic obstructive pulmonary disease (AECOPD). Int J Chron Obstruct Pulmon Dis. 2014;9:99-105. 
17. Laaban JP, Kouchakji B, Dore MF, Orvoen-Frija E, David P, Rochemaure J. Nutritional status of patients with chronic obstructive pulmonary disease and acute respiratory failure. Chest. 1993;103: 1362-1368.

18. Ai-Ping C, Lee KH, Lim TK. In-hospital and 5-year mortality of patients treated in the ICU for acute exacerbation of COPD: a retrospective study. Chest. 2005;128:518-524.

19. Ucgun I, Metintas M, Moral H, Alatas F, Yildirim H, Erginel S. Predictors of hospital outcome and intubation in COPD patients admitted to the respiratory ICU for acute hypercapnic respiratory failure. Respir Med. 2006;100:66-74.

20. Chu CM, Chan VL, Lin AW, Wong IW, Leung WS, Lai CK. Readmission rates and life threatening events in COPD survivors treated with non-invasive ventilation for acute hypercapnic respiratory failure. Thorax. 2004;59:1020-1025.

21. Titlestad IL, Lassen AT, Vestbo J. Long-term survival for COPD patients receiving noninvasive ventilation for acute respiratory failure. Int J Chron Obstruct Pulmon Dis. 2013;8:215-219.

22. Aaron SD. Management and prevention of exacerbations of COPD. BMJ. 2014;349:g5237.

23. Poole PJ, Chacko E, Wood-Baker RW, Cates CJ. Influenza vaccine for patients with chronic obstructive pulmonary disease. Cochrane Database Syst Rev. 2000;2006:CD002733.

24. Karner C, Chong J, Poole P. Tiotropium versus placebo for chronic obstructive pulmonary disease. Cochrane Database Syst Rev. 2012;7: CD009285.

25. Schols AM, Ferreira IM, Franssen FM, et al. Nutritional assessment and therapy in COPD: a European Respiratory Society statement. Eur Respir J. 2014;44:1504-1520.

26. Hurst JR, Donaldson GC, Wilkinson TM, Perera WR, Wedzicha JA. Epidemiological relationships between the common cold and exacerbation frequency in COPD. Eur Respir J. 2005;26:846-852.

27. WilkinsonTM,HurstJR,PereraWR, Wilks M,Donaldson GC, WedzichaJA. Effect of interactions between lower airway bacterial and rhinoviral infection in exacerbations of COPD. Chest. 2006;129:317-324.
28. Sapey E, Stockley RA. COPD exacerbations. 2: aetiology. Thorax. 2006; 61:250-258.

29. Yang CY, Chen CJ. Air pollution and hospital admissions for chronic obstructive pulmonary disease in a subtropical city: Taipei, Taiwan. J Toxicol Environ Health A. 2007;70:1214-1219.

30. Funk GC, Bauer P, Burghuber OC, et al. Prevalence and prognosis of COPD in critically ill patients between 1998 and 2008. Eur Respir J. 2013;41:792-799

31. Zilberberg MD, Stern LS, Wiederkehr DP, Doyle JJ, Shorr AF. Anemia, transfusions and hospital outcomes among critically ill patients on prolonged acute mechanical ventilation: a retrospective cohort study. Crit Care. 2008;12:R60.

32. Cote C, Zilberberg MD, Mody SH, Dordelly LJ, Celli B. Haemoglobin level and its clinical impact in a cohort of patients with COPD. Eur Respir J. 2007;29:923-929.

33. Girón R, Matesanz C, García-Río F, et al. Nutritional state during COPD exacerbation: clinical and prognostic implications. Ann Nutr Metab. 2009;54:52-58.

34. Alonso Martinez JL, Abinzano Guillén ML, Martínez Velasco C, García Mouriz ME. [Morbidity and mortality among the hospitalized aged. Identification of prognostic factors]. An Med Interna. 1995;12: 420-424. Spanish.

35. Aguayo-Becerra OA, Torres-Garibay C, Macías-Amezcua MD, et al. Serum albumin level as a risk factor for mortality in burn patients. Clinics (Sao Paulo). 2013;68:940-945.

36. Yang SS, Yu CS, Yoon YS, Yoon SN, Lim SB, Kim JC. Risk factors for complications after bowel surgery in Korean patients with Crohn's disease. J Korean Surg Soc. 2012;83:141-148.

37. Rujirojindakul P, Geater AF, McNeil EB, et al. Risk factors for reintubation in the post-anaesthetic care unit: a case-control study. $\mathrm{Br} J$ Anaesth. 2012;109:636-642.
International Journal of COPD

\section{Publish your work in this journal}

The International Journal of COPD is an international, peer-reviewed journal of therapeutics and pharmacology focusing on concise rapid reporting of clinical studies and reviews in COPD. Special focus is given to the pathophysiological processes underlying the disease, intervention programs, patient focused education, and self management protocols.

\section{Dovepress}

This journal is indexed on PubMed Central, MedLine and CAS. The manuscript management system is completely online and includes a very quick and fair peer-review system, which is all easy to use. Visit http://www.dovepress.com/testimonials.php to read real quotes from published authors. 